\title{
CONVENÇĀO EUROPÉIA DE DIREITOS HUMANOS E CONVENÇĀO AMERICANA DE DIREITOS HUMANOS EM COMPARAÇÃO
}

BEATRIZ SCHIFFER DURÃES *

SUMĀRIO: Origem. Estados Membros. Texto. Objetivo. Estrutura. Organização. Competência. Procedimento.

\section{ORIGEM}

Se nos voltarmos para o século XIII na Inglaterra, quando foi estabelecida a Magna Carta de 1215 como alicerce das liberdades do homem, ou então para o século XVIII, quando foi promulgada a Declaração Francesa dos Direitos do Homem e do Cidadão em $1789^{1}$, constatamos que esforços sempre têm sido feitos para encontrar soluções que tornariam a humanidade capaz de alcançar um mundo de paz e liberdade.

A origem do sistema inter-americano pode ser atribuída ao Congresso do Panamá de 1826, onde uma Confederação de Estados Latino-Americanos e um Tratado de União Perpétua, Liga e Confederação foram adotados. A este aderiram Colômbia (incluindo Equador, Panamá e Venezuela), México, América Central e Perú, não vindo nunca a entrar em vigor pelo fato de apenas ter sido ratificado por Colômbia. Subseqüentemente, a convite dos Estados Unidos, reuniram-se dezessete Repúblicas Americanas para uma Primeira Conferência Americana Internacional em Washington, que se realizou de outubro de 1889 a abril de 1890. Nesta ocasião foi fundada a União Internacional

* Advogada diplomada pela Faculdade de Direito da Universidade Federal do Paraná. Trabalho final do Curso de Estudos Internacionais realizado na Faculdade de Jurisprudência da Universidade de Viena. 
das Repúblicas Americanas, comumente conhecida como a União Pan-Americana. Como funções principais, promovia cooperação econômica e a resolução pacífica de disputas ${ }^{2}$.

Retornando ao século XX, o Presidente dos Estados Unidos, Franklin Roosevelt, e o Primeiro Ministro do Reino Unido, Winston Churchill, lançaram em agosto de 1941 as Quatro Liberdades na Carta do Atlântico ("Atlantic Charter"), tendo tal documento sido posteriormente subscrito e endossado por quarenta e sete nações de todos os continentes.

Mas no período logo após a Segunda Guerra Mundial, quando agressões aos direitos e liberdades inerentes aos seres humanos haviam sido cometidas pelas atrocidades e horrores daquela época, um interesse internacional em promover e encorajar o respeito pelos direitos humanos emergiu, e um plano internacional de ação positiva foi reivindicado.

A Carta das Nações Unidas foi assinada em 1945 e a Declaração Universal dos Direitos Humanos foi adotada em Dezembro de 1948 pela Assembléia Geral da citada organização ${ }^{3}$.

Nesse meio tempo, com relação ao sistema inter-americano, a Nona Conferência Internacional dos Estados Americanos, realizada em Bogotá durante maio de 1948, adotou uma Carta que fornecia o novo instrumentc constitucional necessário, e portanto estabeleceu a Organização dos Estados Americanos (OEA). A Carta do CEA entrou em vigor em 1951. Na mesma Conferência, a Declaração Americana dos Direitos e Deveres do Homem foi proclamada sob a forma de uma simples resolução ${ }^{4}$.

No Continente Europeu, também se davam os primeiros passos em direção à realização dos direitos humanos e liberdades fundamentais. Devido a conflitos ideológicos entre Europa Oriental e Ocidental, o perigo de um sistema ditatorial na Europa Ocidental era muito real àquela época. Em maio de 1948, o Comitê Internacional dos Movimentos pela União Européia organizou um "Congresso da Europa" em Haia, cuja finalidade era de demonstrar o amplo apoio à causa da união européia. Tal iniciativa deu ímpeto decisivo para a fundação do Conselho da Europa em 1949, cujos objetivos eram de obter a união entre seus membros, proteger e promover o ideal e os princípios da democracia, e facilitar a seus membros o progresso econômico e social. Tão logo o Conselho da Europa se reuniu para sua primeira sessão em agosto de 1949, tomou providências para formular uma Convenção estabelecendo uma garantia coletiva e projetada para assegurar o gozo efetivo dos direitos e liberdades proclamados na De- 
claração Universal dos Direitos Humanos. A Convenção foi assinada em Roma no dia 04 de novembro de 1950, entrando em vigor no dia 03 de setembro de 1953, após o décimo instrumento de ratificação ${ }^{5}$.

Ao contrário do sistema americano, a Convenção Européia de Direitos Humanos desenvolveu-se em um período de cinco anos, enquanto que para estabelecer uma Convenção no sistema americano, problemas foram surgindo até a Conferência de São José (Costa Rica) em novembro de 1969. Tais problemas diziam respeito à falta de condição de lei substantiva positiva da Declaração de Bogotá, ou seja, não havia nenhuma obrigação contratual para as partes que ratificavam tal documento. Também a Carta da OEA não estabelecia nenhum procedimento para assegurar a implantação dos direitos ali contidos. Tentativas para estabelecer uma estrutura institucional para a promoção dos direitos humanos estavam sempre sendo feitas dentro do sistema inter-americano. O Quinto Encontro do Conselho de Ministros das Relações Exteriores, em Santiago no ano de 1959, criou a Comissão InterAmericana de Direitos Humanos, a qual em 1960 foi definida como uma entidade autônoma da OEA. Durante este encontro, foi também declarado que "para os fins deste Estatuto, entendese que direitos humanos são aqueles expostos na Declaração Americana dos Direitos e Deveres do Homem".

Violações em larga escala aos direitos humanos realmente prevaleciam em várias Repúblicas Americanas, entretanto, uma solução para estas agressões tinha de ser encontrada imediatamente.

Em resposta a tais problemas e necessidades no Continente Americano, em 1965 no Rio de Janeiro a Segunda Conferência Especial Inter-Americana ampliou os poderes da Comissão em uma quantidade de aspectos significativos, que se referiam não apenas à promoção, mas também à proteção dos direitos humanos, como por exemplo a possibilidade da Comissão de examinar comunicações de indivíduos acusando violações de tais direitos. Mas faltava ao sistema uma base constitucional sólida porque a Comissão foi designada como uma "entidade autônoma" da OEA, ou seja, não estava qualificada nem como um órgão do Conselho da OEA nem como um órgão especializado da OEA. Outrossim, os direitos humanos cuja promoção e observância cabia à Comissão assegurar, haviam sido proclamados na Declaração Americana dos Direitos e Deveres do Homem, um instrumento não considerado como criando obrigações legais represen- 
tativas de compromisso para qualquer Estado Membro da OEA.

Com a entrada em vigor da Carta revisada (Protocolo de Buenos Aires, concluído em 1967 e passando a vigorar em 1970), a Comissão Inter-Americana de Direitos Humanos foi transformada em um dos principais órgãos da Organização, derivando sua existência bem como seus poderes de um tratado multilateral devidamente ratificado.

A Carta, assim retificada, estipulava também que a Comissão continuaria seu trabalho até a entrada em vigor de uma Convenção Inter-Americana de Direitos Humanos, que determinaria a estrutura, competência e procedimento da Comissão.

A Convenção Americana de Direitos Humanos foi considerada e adotada na Conferência Inter-Americana Especializada em Direitos Humanos realizada em São José, Costa Rica durante novembro de 1969, e baseava-se em grande parte no modelo europeu. Entrou em vigor a 18 de julho de 1978 após o décimo instrumento de ratificação ${ }^{6}$.

\section{ESTADOS MEMBROS}

Estados Membros da Convenção Européia de Direitos Humanos ${ }^{7}$

Austria, Bélgica, Chipre, Dinamarca, Espanha, França, Grécia, Irlanda, Islândia, Itália, Liechtenstein, Luxemburgo, Malta, Noruega, Países Baixos, Portugal, Reino Unido, República Federal da Alemanha, Suécia, Suíça, Turquia.

Estados Membros da Convenção Americana de Direitos Humanos ${ }^{8}$

Argentina9 , Barbados, Bolívia, Colômbia, Costa Rica, El Salvador, Equador, Granada, Guatemala, Haiti, Honduras, Jamaica, México, Nicarágua, Panamá, Perú, República Dominicana, Uruguai, Venezuela.

\section{TEXTO}

A Declaração Universal dos Direitos Humanos, bem como a Carta das Nações Unidas, estipulam, a um plano substantivo, a fonte normativa para os instrumentos de direitos humanos de organizações regionais e especializadas, como por exemplo a 
Convenção Européia de Direitos Humanos e a Convenção Americana de Direitos Humanos ${ }^{10}$. Em outras palavras, os citados tratados foram influenciados pelo conteúdo normativo da Declaração Universal dos Direitos Humanos, e uma interação entre os esforços das Nações Unidas e ambas as Convenções para implementar direitos humanos se firmou.

A Convenção Americana de Direitos Humanos considera não só a Declaração Universal dos Direitos Humanos, mas também a Carta da OEA, a Declaração Inter-Americana dos Direitos e Deveres do Homem, bem como outros instrumentos internacionais e regionais ${ }^{11}$, ou seja, de uma maneira indireta, inclusive também a Convenção Européia.

A Convenção Européia contém 66 artigos divididos em cinco secções referentes a direitos civis e políticos, o procedimento da Comissão e da Corte e algumas cláusulas gerais. Oito protocolos adicionais foram estabelecidos, sendo que o sétimo e oitavo não entraram ainda em vigor.

O texto da Convenção Americana é mais longo, compreendendo 82 artigos, divididos em três partes. A primeira é subdividida em cinco capítulos concernentes a direitos civis e políticos, bem como a direitos econômicos, sociais e culturais. O Artigo 26 estabelece: “. . . a plena realização dos direitos implícitos nas normas econômicas, sociais, educacionais, científicas e culturais descritas na Carta da OEA, conforme emendada pelo Protocolo de Buenos Aires".

Além disso, a Convenção Americana inclui outros artigos não estabelecidos pelo sistema europeu, ou seja, o direito de reconhecimento da pessoa perante a lei (Artigo 3), direito ao nome (Artigo 18), direitos da criança (Artigo 19), direito à nacionalidade (Artigo 20), direito à igualdade perante a lei (Artigo 24).

Parte II contém quatro capítulos estabelecendo o procedimento da Comissão e da Corte, e Parte III, dividida em dois capítulos, diz respeito a provisões gerais e transitórias.

Comparando Artigo 4 (2) da Conveção Americana com Artigo 2 da Convenção Européia, ambos sistemas mencionam a execução da pena de morte referente à lei do respectivo Estado que ainda não a aboliu. Mas segundo o novo Protocolo 6 da Convenção Européia, assinado em abril de 1983 e tendo entrado em vigor em março de 1985, a pena de morte é expressamente proibida. Artigo 1 estabelece que a pena de morte será abolida e ninguém será condenado a tal penalidade ou executado. 
Como a pena de morte é uma ação contrária aos princípios baseados nos direitos essenciais e inerentes ao homem, medidas devem ser tomadas a fim de implantar sua proibição no sistema americano.

Texto da Convenção Européia de Direitos Humanos

Artigo 10 .

Secção I-Art. 2-18

Secção II - Art. 19

Secção III - Art. 20 - 37 Comissão

Secção IV - Art. 38 - 56 Corte

Secção V - Art. $57-66$

Protocolo $\quad 1$ - direitos civis e políticos, outros que não aqueles estabelecidos na Secção I;

Procotolo II - confere à Corte competência para dar opinião em forma de parecer;

Protocolo III - procedimento da Comissão;

Protocolo IV - direitos civis e políticos;

Protocolo V-eleição de membros da Comissão e da Corte;

Protocolo VI - proibição da condenação e execução da penalidade de morte.

Protocolo VII - direitos civis e políticos;

Protocolo VIII - modificações de alguns artigos referentes à procedimentos $(20,21,23,28, \ldots \ldots \ldots \ldots \ldots)$.

Texto da Convenção Americana de Direitos Humanos

Parte I - Obrigações do Estado e Direitos Protegidos

Capítulo 1 - Obrigações Gerais Art. $1-2$

Capítulo 2-Direitos Civis e Políticos Art. 3-25

Capítulo 3 - Direitos Econômicos, Sociais e Culturais

Art. 26

Capítulo 4 - Suspensão de Garantias, Interpretação e Aplicação

Art. $27-31$

Capítulo 5-Responsabilidades Pessoais

Art. 32 
Parte II - Meios de Proteção

Capítulo 6-Órgãos Competentes

Art. 33

Capítulo 7 - Comissão Inter-Americana de

$$
\text { Direitos Humanos Art. 34-51 }
$$

Capítulo 8 - Corte Inter-Americana de Direitos Humanos

Art. $52-69$

Capítulo 9 - Provisões Comuns

Art. $70-73$

Parte III - Provisões Gerais e Transitórias

$\begin{aligned} & \text { Capítulo } 10 \text { - } \text { Assinatura, Ratificações, Emendas, } \\ & \text { Protocolos e Denúncias } \\ & \text { Art. 74- } 78 \\ & \text { Capítulo } 11 \text { - Provisões Transitórias } \text { Art. 79-82 }\end{aligned}$

\section{OBJETIVO}

O objetivo de ambas Convenções está diretamente ligado a suas origens.

Como já dito anteriormente, estabeleceu-se na Europa um sistema para concretizar os direitos humanos e liberdades fundamentais, como uma reação contra os regimes nazista e fascista. Foi exigida então, uma proteção contra o possível renascimento de uma ditadura, ou seja, contra qualquer outro sistema que não a democracia, e como resultado, a Convenção Européia de Direitos Humanos foi estabelecida.

O sistema americano também foi desenvolvido de acordo com as necessidades referentes às relações entre indivíduos e seus próprios países. Muitas formas de comportamento não civilizado, como por exemplo prisão arbitrária, detenção sem julgamento, execução política, tortura, etc., tornavam evidente a necessidade de uma proteção a fim de eliminar, ou pelo menos reduzir, o número de violações ocorrentes.

O objetivo das citadas Convenções é o mesmo. Ambas pretendem a realização dos direitos humanos e liberdades fundamentais, ou seja, democracia.

\section{ESTRUTURA}

O procedimento das Convenções Européia e Americana de Direitos Humanos consiste em duas fases: 
- o procedimento perante a Comissão de Direitos Humanos;

- o procedimento perante a Corte de Direitos Humanos ${ }^{12}$.

A Convenção Européia é um sistema de garantia coletiva tendo em vista a conservação e realização dos direitos humanos e liberdades fundamentais através da união de seus membros ${ }^{13}$. Uma Comissão foi estabelecida para assegurar a observância dos compromissos assumidos pelas Altas Partes Contratantes. É um órgão da Convenção originado pela mesma.

A Comissão Inter-Americana de Direitos Humanos, por outro lado, é um órgão da OEA, criado para promover a observância e defesa dos direitos humanos e para servir como órgão consultivo da organização nesta questão. Como já dito anteriormente, a origem da Comissão americana pode ser atribuída ao Quinto Encontro do Conselho de Ministros das Relações Exteriores em Santiago, no ano de 1959. Primeiramente, como uma entidade autônoma da organização, através do Protocolo de Buenos Aires de 1967, a Comissão foi transformada em um dos principais órgãos da OEA, continuando assim o seu trabalho, até a entrada em vigor da Convenção Americana de Direitos Humanos a qual determinaria a estrutura, competência e procecimento da Comissão. Assim que a Convenção Americana de Direitos Humanos entrou em vigor, uma evolução em termos de um sistema efetivo para promover e proteger os direitos humanos foi concretizado, estabelecendo a competência da Comissão Inter-Americana de Direitos Humanos em tratado.

No que diz respeito à jurisdição de cada Comissão, distinções devem ser salientadas.

A jurisdição da Comissão Européia estende-se somente até os Estados Membros da Convenção, enquanto a Comissão InterAmericana estende sua jurisdição não só aos Estados Membros da Convenção, mas também a todos os Estados Membros da OEA ${ }^{14}$. A Comissão trabalha em nome dos Estados Membros da Convenção no que concerne aos direitos estabelecidos na Convenção, e também trabalha em nome dos Estados Membros da OEA que não ratificaram a Convenção, no que se refere aos direitos estabelecidos na Declaração Americana de Direitos e Deveres do Homem. Artigo 10., Parágrafo 20. do Estatuto da Comissão InterAmericana de Direitos Humanos declara:

"Para os objetivos do presente Estatuto, direitos humanos são entendidos como sendo:

- a. os direitos estabelecidos na Convenção Americana de Direitos Humanos, em relação aos Estados Membros 
que ratificaram tal instrumento;

- b. os direitos estabelecidos na Declaração dos Direitos e Deveres do Homem, em relação aos outros Estados Membros".

São claramente distinguidos pelo novo Estatuto, o poder da Comissão referente aos Estados Membros da Convenção e aos países que não fazem parte deste instrumento. No que diz respeito aos países não pertencentes à Convenção, a jurisdição resulta de prática anterior da Comissão, bem como da Carta da OEA, enquanto em relação aos Estados Membros da Convenção, o poder é emanado deste instrumento.

Segundo ambas as Convenções, após uma queixa ter sido declarada admissível pela Comissão e esforços em alcançar um entendimento ámigável entre as partes terem falhado, o caso pode ser submetido à Corte $^{15}$.

Tanto a Corte Européia como a Americana, são órgãos que foram criados pela entrada em vigor de suas respectivas Convenções, e a competência para examinar um caso se estende somente aos Estados Membros de tais tratados. Exercem jurisdição adjudicatória e consultiva e, em relação a esta última, o sistema americano confere tal poder a todos os Estados Membros da $\mathrm{OEA}^{16}$. Por outro lado, o Protocolo 2 da Convenção Européia estabelece que a Corte deve, a pedido do Comitê de Ministros, exercer jurisdição consultiva em questões legais concernentes à interpretação da Convenção e de seus respectivos protocolos.

A jurisdição da Corte pode ser ou não ser aceita pelo Estado Membro. Uma declaração opcional pode ser entregue ao Secretário Geral da Convenção (tanto da Convenção Americana coma da Convenção Européia), pela qual o Estado reconhece como compulsória, a jurisdição da Corte em todas as questões concernentes a interpretação e aplicação da Convenção ${ }^{17}$. Ao invés de reconhecer antecipadamente a jurisdição da Corte através da chamada "declaração opcional", um Estado pode consentir "ad hoc" na consideração de um determinado caso pela Corte. Este ato pode ser praticado explicitamente através de uma declaração unilateral do Estado em questão ${ }^{18}$.

Nos casos em que a jurisdição da Corte não for aceita, uma distinção entre ambos os sistemas deve ser apontada.

De acordo com a Convenção Européia, após a Comissão ter examinado os méritos da causa, esta redige um relatório que deverá ser transmitido para o Comitê de Ministros do Conselho da Europa. Após três meses a contar da data da transmissão 
do relatório para o Comitê de Ministros, desde que dentro deste período o caso não tenha sido referido à Corte pelo fato da não aceitação da jurisdição pelo Estado em questão, o Comitê de Ministros exerce uma função judicial na segunda fase do procedimento supervisório, decidindo por sua vez se houve ou não violação à Convenção ${ }^{19}$. O Comitê de Ministros é um órgão político do Conselho da Europa, mas neste caso (não aceitação da jurisdição da Corte pelo Estado em questão e, conseqüentemente, não apresentação à Corte), o Comitê de Ministros exerce função judicial.

Por outro lado, nos casos em que a jurisdição da Corte Inter-Americana de Diretos Humanos não for aceita, o órgão que irá decidir se houve violação à Convenção é a Comissão Inter-Americana de Direitos Humanos, um órgão da OEA ${ }^{20}$.

Em outras palavras, o Comitê de Ministros como órgão do Conselho da Europa, bem como a Comissão Inter-Americana como órgão da OEA, ambos exercem função judicial na segunda fase do procedimento nos casos em que a jurisdição da Corte não foi aceita, ou se o caso não foi referido à Corte devido a outras razões.

\section{Convenção Européia de Direitos Humanos}

Comissão - um órgão da Convenção Européia;

- sua jurisdição se estende somente aos Estados Membros da Convenção.

Corte - jurisdição consultiva;

jurisdição adjudicatória.

$$
\begin{gathered}
\text { Comitê de Ministros - um órgão do Conselho da } \\
\text { Europa. }
\end{gathered}
$$

\section{Convenção Americana de Direitos Humanos}

Comissão - um órgão da OEA;

- sua jurisdição se estende aos Estados Membros que não ratificaram a Convenção no que concerne aos direitos expostos na Declaração Americana dos Direitos e Deveres do Homem;

- sua jurisdição em relação aos Estados Membros da 
Convenção será com referência aos direitos estabelecidos naquele instrumento.

Corte - jurisdição consultiva;

- jurisdição adjudicatória.

Comissão Inter-Americana de Direitos Humanos - um órgão da OEA

\section{ORGANIZAC̣ĀO}

Comissão Européia

1 - Número de Membros da Comissão ${ }^{21}$

- igual ao número de Membros da Convenção: vinte e um Membros

2 - Eleição dos Membros da Comissão ${ }^{22}$ :

- eleitos pelo Comitê de Ministros de uma lista de nomes elaborada pelo Gabinete da Assembléia Consultiva

3 - Membros são eleitos para um período $\mathrm{de}^{23}$ :

- seis anos e uma re-eleição é possível

4 - O Presidente e o primeiro e segundo Vice-Presiaientes são eleitos por $^{24}$ :

- três anos
5 - Membros eleitos na primeira eleição ${ }^{25}$ :

- os mandatos de sete Membros expirarão ao final de três anos

6 - Sede da Comissão ${ }^{26}$ :

- Strassbourg (França)

7 - As sessões da Comissão ${ }^{27}$ :

- cinco sessões ordinárias de duas semanas cada por ano

8 - Idiomas oficiais ${ }^{28}$ :

- Inglês e Francês
Comissão Inter-Americana

- sete Membros que representarão todos os Estados Membros da OEA

- eleitos pela Assembléia Geral da Organização de uma 
lista de candidatos propostos pelos governos dos Estados Membros

- quatro anos e só podem ser re-eleitos uma única vez

- um ano

- os mandatos de três Membros expirarão ao final de dois anos

- Washington, D. C. (EUA)

- não excedendo um total de oito semanas por ano

- Espanhol, Inglês, Francês

\section{Comissão Européia}

1 - Número de Membros da Corte $^{29}$ :

- igual ao número de Membros do Conselho da Europa: vinte e um Membros

2 - Eleição dos Membros da Corte $^{30}$ :

- eleitos pela Assembléia Consultiva de uma lista de pessoas nomeadas pelos Membros do Conselho da Europa

3 - Membros eleitos por um período de $\mathrm{de}^{31}$ :
- nove anos e eles podem ser re-eleitos

4 - Membros eleitos na primeira eleição ${ }^{32}$ :

- os mandatos de quatro Membros expirarão ao final de três anos e os mandatos de outros quatro Membros expirarão ao final de seis anos

5 - Sede da Corte ${ }^{33}$ :

- Strassbourg (França)

6 - Quorum da Corte ${ }^{34}$ :

- doze juízes constituirão um quorum

7 - Estados que reconheceram a competência da Corte $^{35}$ :

- dezenove Estados: Áustria, Bélgica, Chipre, Dinamarca, França, República Federal da Alemanha, Grécia, Islândia, Irlanda, Itália, Liechtenstein, Luxemburgo, Países Baixos, Noruega, Portugal, Espanha, Suécia, Suíça, Reino Unido.

Corte Inter-Americana

- São José (Costa Rica)

- cinco juízes constituirão um quorum 
- oito Estados:

Perú, Costa Rica, Honduras, Equador, Colômbia, Argentina, Venezuela, Uruguai.

- a Corte consistirá de sete juízes

- eleitos pelos Estados Membros da Convenção na Assembléia Geral da OEA, de um painel de candidatos propostos por aqueles Estados

- seis anos e eles podem ser re-eleitos apenas uma única vez

- os mandatos de três juízes expirarão ao final de três anos

\section{COMPETENCIA}

\section{Competência "Ratione Loci"}

De acordo com os Artigos 1 e 14 da Convenção Européia, e Artigo 1 da Convenção Americana, os direitos e liberdades estabelecidos nas mesmas estarão assegurados a todos que estiverem sujeitos às respectivas jurisdições, sem nenhuma forma de discriminação.

Como regra geral de direito internacional, a jurisdição de ambas as Convenções estende-se não apenas a todo o território dos Estados Membros, como também aos territórios por cujas relações internacionais o Estado em questão é responsável, como por exemplo a Dinamarca em relação à Groenlândia, e o Reino Unido com respeito aos territórios pertencentes à Comunidade Britânica ${ }^{36}$.

Entretanto, em relação à Convenção Européia, há uma limitação quanto a este assunto imposta pelo Artigo 63 (1) que não se encontra estabelecida no sistema americano. Exige-se uma declaração referente à extensão da jurisdição da Convenção Européia aos territórios por cujas relações internacionais o Estado é responsável. Tais territórios somente serão reconhecidos pela Convenção Européia após esta notificação, endereçada ao Secretário Geral do Conselho da Europa.

Tal declaração não é imposta pela Convenção Americana, e como conseqüência, os territórios pertencentes ao Estado Membro em questão estão automaticamente vinculados à jurisdição da Convenção, como estabelecem as normas internacionais. 


\section{COMPETẼNCIA “RATIONE PERSONAE"}

\section{Requerimentos Inter-Estaduais}

Ambas Convenções são competentes para receber e examinar comunicações de um Estado Membro alegando uma violação dos direitos das Convenções cometida por outro Estado Membro $^{37}$.

Entretanto, o sistema americano estabelece um caráter opcional no que concerne à competência da Comissão para receber petições de Estados Partes. De acordo com o Artigo 45 da Convenção Americana, um Estado Parte pode declarar que reconhece a competência da Comissão para receber e examinar comunicações nas quais alega que outro Estado Parte cometeu uma violação dos direitos humanos estabelecidos naquele instrumento, e tal comunicação somente pode ser admitida e examinada pela Comissão se o Estado acusado também fizer tal declaração. Em outras palavras, um Estado Membro somente pode trazer uma ação internacional contra outro Estado Membro, se ambos tiverem feito uma declaração reconhecendo a competência da Comissão para receber e examinar comunicações dos Estados.

Em contraste a isto, o Artigo 24 da Convenção Européia não estabelece nenhuma declaração concernente aos requerimentos inter-estaduais, afirmando apenas que toda Parte Contratante pode levar ao conhecimento da Comissão qualquer suposta quebra das provisões da Convenção por outra Parte Contratante. Um Estado pode registrar queixas sobre violações cometidas contra pessoas que são seus cidadãos de qualquer dos Estados contratantes, e sobre violações contra cidadãos do Estado acusado. Estados podem também registrar uma queixa sobre a incompatibilidade da legislação nacional ou da prática administrativa de outro Estado (requerimentos abstratos - "actio popularis") para com a Convenção. Não se exige qualquer relação especial entre os direitos e interesses do Estado requerente e as supostas violações ${ }^{38}$.

Vindo para o continente americano, não se supõe que um Estado registre queixas sobre violações cometidas contra pessoas por um outro Estado, uma vez que o direito dos indivíduos de darem entrada em petições tem um caráter obrigatório (não é exigida qualquer declaração especial reconhecendo a competência da Comissão para receber petições de indivíduos); e o mesmo se 
aplica naqueles casos referentes a requerimentos abstratos ("'actio popularis"'), que são vistos como um ato diplomático inamistoso.

\section{Requerimentos Individuais}

Qualquer pessoa ou grupo de pessoas, ou qualquer entidade não-governamental pode registrar junto à respectiva Comissão petições contendo denúncias de violações dos direitos e liberdades estabelecidos por ambas Convenções ${ }^{39}$.

Diferenças também devem ser salientadas aqui. Em primeiro lugar, de acordo com o Artigo 25 da Convenção Européia, a Comissão receberá um requerimento individual se o requerente alegar ser a vítima de uma violação dos direitos protegidos. Qualquer um que tenha sofrido uma violação dos direitos estabelecidos por esta Convenção, ou qualquer um que tenha genuíno interesse pessoal no término da violação declarada na petição, terá o direito de registrar uma queixa junto à Comissão. Outrossim, uma declaração reconhecendo a competência da Comissão para receber tais petições está estabelecida pelo sistema europeu. A violação alegada deve ter sido cometida por uma Alta Parte Contratante que tenha reconhecido o direito das reclamações individuais.

A Comissão Inter-Americana também aceitará uma petição de qualquer pessoa ou grupo de pessoas, ou qualquer entidade não governamental, a qual contenha denúncias de violações desta Convenção por um Estado Parte. Mas não é necessário que o signatário da petição reclame ser a vítima, nem se exige qualquer interesse pessoal no caso. Além disso, não há qualquer declaração especial reconhecendo a competência da Comissão para receber petições de indivíduos, ou seja, o direito do indivíduo de encaminhar uma petição à Comissão tem um caráter obrigatório.

Em outras palavras, de acordo com o sistema europeu, o direito de queixa do indivíduo é opcional porque uma declaração reconhecendo a competência da Comissão para receber tal petição é exigida, enquanto o mecanismo entre Estados é obrigatório, o que significa que nenhuma declaração é exigida. Em contraste a isto, o sistema americano estabelece um caráter opcional aos requerimentos por parte dos Estados e um mecanismo obrigatório para queixas individuais. 


\section{Convenção Européia}

- Requerimentos Inter-Estaduais

obrigatórios

- Requerimentos Individuais

opcionais

\section{Convenção Americana}

- Requerimentos Inter-Estaduais

opcionais

- Requerimentos Individuais

obrigatórios

\section{Competência "Ratione Temporis"}

Uma regra geral de Direito Internacional declara que um tratado não é aplicável a atos ou fatos que já ocorreram antes do mesmo entrar em vigor ou ser ratificado pelos Estados em questão.

A declaração exigida pelo Artigo 25 da Convenção Européia, 'reconhecendo a competência da Comissão para receber requerimentos de indivíduos, tem efeito retroativo até o momento de ratificação da Convenção ${ }^{40}$, desde que a Convenção constituísse compromisso para o Estado. $\mathrm{O}$ mesmo pode ser aplicado ao Artigo 45 da Convenção Americana, que estabelece tal declaração quanto ao direito dos requerimentos dos Estados.

Por outro lado, a questão do efeito retroativo não desempenha qualquer papel em relação ao Artigo 24 da Convenção Européia concernente aos requerimentos Inter-Estaduais, ou ao Artigo 44 da Convenção Americana com referência aos requerimentos individuais, uma vez que não é exigida nenhuma declaração a fim de reconhecer a competência da Comissão para receber e examinar tais petições.

\section{Competência "Ratione Materiae"}

Uma série de direitos civis e políticos, assim como um mecanismo para a implementação desses direitos, são oferecidos aos indivíduos e Estados Partes de ambas Convenções.

Entretanto, o Artigo 26 do sistema americano reforça os direitos econômicos, sociais e culturais expostos na Carta da OEA, declarando que os Estados Membros devem adotar medidas para a plena realização dos mencionados direitos. 


\section{PROCEDIMENTO}

Cinco requisitos são necessários para um completo sistema de controle da observância dos direitos humanos: informação, investigação, conciliação, decisão e sanção. ${ }^{41}$

Como órgãos permanentes quase-judiciais, a Comissão Européia de Direitos Humanos e a Comissão Inter-Americana de Direitos Humanos ocupam-se de situações concretas, realizando as funções acima mencionadas, ou seja, informação, investigação, conciliação, e não tomando decisões que constituam compromisso legal, mas decidindo aceitar ou rejeitar a petição no decurso do exame. Mas com referência ao sistema americano, nos casos em que a jurisdição da Corte Inter-Americana de Direitos Humanos não é aceita, o órgão que decidirá se houve violação da Convenção é a Comissão Inter-Americana de Direitos Humanos. Ela desempenha uma função judicial na segunda fase do procedimento, quer dizer, toma decisões que constituem compromisso legal.

Ambas Comissões agem inicialmente através de suas Secretarias, recebendo petições e processando-as. Mediante a aceitação, em princípio, da admissibilidade de um tal requerimento, as Comissões solicitarão informações do governo do Estado contra o qual a queixa foi feita ${ }^{42}$.

De acordo com a Regra 39 das Regras de Procedimento da Comissão Européia de Direitos Humanos, se o requerimento for trazido por um Estado, o Presidente da Comissão notifica o Estado contra quem a queixa é feita e o convida a submeter observações por escrito sobre a admissibilidade.

Entretanto, a Regra 40 determina que no caso de uma queixa individual, um relator é nomeado para apresentar um relatório sobre a admissibilidade. Ele deve solicitar informações do requerente e do Estado atingido e, após coletá-las, comunicar as informações obtidas do Estado ao requerente para comentários. A Comissão considerará o relatório do relator e, se for o caso, pode não admitir o requerimento. De outra maneira, aceitando-o, a Comissão pode convidar as partes a submèterem observações adicionais por escrito e/ou oralmente.

A Convenção Americana, por outro lado, não estabelece diferença entre requerimentos do Estado ou de indivíduos neste assunto. Artigo 31 (1c) dos Regulamentos da Comissão Inter-Americana de Direitos Humanos declara que se o citado órgão aceita, em princípio, a admissibilidade da petição, deve- 
rá solicitar informações do governo do Estado contra quem a queixa foi feita.

Após a aceitação preliminar do requerimento, as condições de admissibilidade estabelecidas pelos Artigos 46 - 47 da Convenção Americana e Artigos 26 - 27 da Convenção Européia serão examinadas. Com exceção do Artigo 46 (1d) da Convenção no caso do Artigo 44 (requerimento individual), todos os outros requisitos estabelecidos pelo referido sistema nos Artigos 46 e 47 são válidos para requerimentos submetidos tanto por Estados quanto para aqueles submetidos por indivíduos. O Artigo $27 \mathrm{da}$ Convenção Européia, entretanto, estabelece nada menos do que cinco requisitos válidos para requerimentos apresentados apenas por indivíduos.

Se o requerimento é considerado admissível, conciliação é o próximo passo ${ }^{43}$. Quer dizer, depois que as condições de admissibilidade são examinadas e a petição declarada admissível, a função das Comissões Européia e Inter-Americana é de examinar os méritos a fim de formar uma opinião sobre se houve uma violação das respectivas Convenções e, simultaneamente, tentar assegurar um acerto amigável do assunto com base no respeito pelos direitos humanos.

Com respeito à Convenção Européia, se um acerto amigável é alcançado, a Comissão elabora um relatório o qual será transmitido aos Estados envolvidos, ao Comitê de Ministros, e para publicação ao Secretário Geral do Conselho Europeu. No caso do requerimento individual, o relatório também é transmitido ao requerente individual ${ }^{44}$. De acordo com a Convenção Americana, o relatório será transmitido ao peticionário e, não apenas aos Estados envolvidos como no sistema europeu, mas a todos os Estados Membros da Convenção. Será também comunicado ao Secretário Geral da OEA para publicação ${ }^{45}$.

Se não for alcançado um acerto amigável, a Comissão Européia envia seu relatório ao Comitê de Ministros e àqueles Estados que estiverem envolvidos no caso, não sendo permitido a qualquer destes Estados publicar o conteúdo do citado relatório ${ }^{46}$. Regra 61 das Regras de Procedimento da Comissão prevê que, no caso de um requerimento individual, se este for submetido à Corte, o relatório será enviado ao requerente individual. De outra maneira, se o requerimento é conseqüentemente resolvido pelo Comitê de Ministros, a comunicação do relatório a um requerente individual deve ocorrer somente como uma medida excepcional, e então apenas em base estritamente confidencial e com o con- 
sentimento do Estado contra quem o requerimento foi registrado ${ }^{47}$. A Convenção Americana não estabelece provisão referente à possibilidade do requerente individual receber uma notificação sobre o conteúdo do relatório. O Artigo 50 estabelece que o relatório será transmitido somente aos Estados atingidos, que não terão liberdade para publicá-lo.

O fracasso em alcançar um acerto amigável pelos órgãos quase-judiciais anteriormente citados, torna necessário trazer o caso perante um órgão judicial capaz de tomar decisões judiciais. Este é a Corte Européia de Direitos Humanos ou a Corte InterAmericana de Direitos Humanos. Mas como já foi constatado, a jurisdição das citadas Cortes é opcional, exceto se os Estados Membros das respectivas Convenções tiverem previamente reconhecido a mesma, por meio de declaração, como compulsória em todos os assuntos referentes à interpretação ou aplicação do tratado em questão, ou aceitarem "ad hoc" a jurisdição da Corte.

Se o caso não for referido à Corte dentro de um período de três meses, o Comitê de Ministros considerará o caso sob o sistema europeu e, sob o sistema americano, a Comissão InterAmericana decidirá se houve uma violação da Convenção. Tais decisões constituem compromisso para os governos e devem ser acompanhadas por opiniões e recomendações no sentido de que o Estado deve remediar a situação examinada num período prescrito. Se o Estado falhar na execução das medidas adequadas, quer dizer, não tomar as medidas exigidas para compensar a não observância dos direitos humanos, o relatório é publicado como uma forma de sanção $0^{48}$.

Artigo 44 da Convenção Européia e Artigo 61 da Convenção Americana estabelecem que somente a Comissão e o Estado Membro têm o direito de apresentar um caso perante a Corte ${ }^{49}$. A primeira não aparece como parte, mas como representante do interesse público, agindo em nome dos governos e das pessoas. Este último (Estado Membro), tem de provar que submeteu o caso à Comissão, ou que ele é o Estado contra quem a queixa foi registrada, ou que a suposta vítima é seu cidadão. $O$ requerente individual não pode trazer um caso perante a Corte. Pode ser feito somente através da Comissão ou através do Estado contratante que submeteu o caso à Comissão ou o Estado contratante de quem a suposta vítima é cidadão.

Em ambos os sistemas, a Corte deve decidir se houve uma quebra da Convenção e, se for assim, quais direitos a serem 
concedidos à parte prejudicada. Pode também determinar as providências que devem ser tomadas para remediar a quebra e o montante de indenização à qual a parte prejudicada tem direito. Sentenças da Corte são finais ${ }^{50}$, e assim, os procedimentos descritos chegam a uma conclusão.

Somente a opinião pública será capaz de forçar Estados recalcitrantes a obedecerem as respectivas Convenções, pois não há instituições de direitos humanos com meios para obrigar um Estado inadimplente a executar a sentença da Corte ou com poderes para impor sanções.

Uma grande parte do trabalho em favor dos direitos humanos destina-se não apenas à proteção, mas tamgém à promoção dos mesmos. A opinião pública desempenha importante papel para despertar uma conscientização sobre tais direitos ao redor de todo o mundo, e como conseqüência, para estabelecer * "a paz das leis e da justiça, que o mundo ainda não tem porque ainda não crê".

*Oração aos Moços - Rui Barbosa, p. 117. 


\section{NOTAS}

1.Human Rights in the World. A. H. Robertson, p. 5.

2.Protecting Human Rights in the Americas - Selected Problems. Buergenthal, Norris, Shelton, p. $1 / 2$.

3.Theory and Practice of the ECHR. Dijk and Hoof, p. 1.

4. - The OAS. H. G. Espiell, p. 543

- Human Rights - The Inter-American System. Buergenthal \& Norris -

I The Charter of the OAS,

IV The American Declaration of the Rights and Duties of Man.

5. - The Council of Europe. Karel Vasak, p. 457/458

- Theory and Practice of the ECHR. Dijk and Hoof, p. 1/2.

6.- Annual Report of the Inter-American Comission on Human Rights, p. 5

- Preamble of the ACHR

- Protecting Human Rights in the Americas - Selected Problems, p . 5/6

7. Appendix of the ECHR

8.Das inter-amerikanische Menschenrechtssystem, p. 169.

9.Die Entwicklung des internationalen Menschenrechtsschutzes.

Bartch, p. 1757.

10. International and Regional Human Rights Law and Institutions -

Examples of their Interactions, p. 323.

11.Preamble of the ACHR

12.Art. $19 \mathrm{ECHR}$ and Art. $33 \mathrm{ACHR}$

13. Preamble of the ECHR

14.Art. 24 and Art. 25 of the ECHR

Statute of the IACHR, Art. 1

15. Art. 31, 32, 47 of the ECHR

Art. 50, 51, 61 of the ACHR

16.Art. 45 of the ECHR and Art. 64 of the ACHR

17.Art. 46 ECHR and Art. 62 ACHR

18.Theory and Practice of the ECHR. Dijk and Hoof, p. 117

19.Art. 32 ECHR

20. Art. 51 ACHR

21.Art. 34 ACHR and Art. 20 ECHR

22.Art. 36 ACHR and Art. 21 ECHR

23. Art. 37 ACHR and Art. 22 ECHR

24. - Art. 14 of the Statute of the Inter-American Comission

- Rule 6 of the Rules of Procedure of the European Commission

25.Art. 37 ACHR and Art. 22 ECHR

26. - Art. 16 of the Statute of the Inter-American Commission

- Theory and Practice of the ECHR. Dijk and Hoof, p. 20

27. - Art. 13 of the Regulations of the Inter-American Commission

- The and Practice of the ECHR. Dijk and Hoof, p. 20

28. - Rule 24 of the Rules of Procedure of the European Commission

- Art. 22 of the Regulations of the Inter-American Commission

29. Art. 52 ACHR and Art. 38 ECHR

30. Art. 53 ACHR and Art. 39 ECHR

31.Art. 54 ACHR and Art. 40 ECHR

32. Art. 54 ACHR and Art. 40 ECHR

33. - Art. 3 of the Statute of the Inter-American Court

- The Council of Europe. Karel Vasak, p. 514

34. - Art. 23 of the Statute of the Inter-American Court

- Rule 16 of the Rules of Procedure of the European Court

35. - The Council of Europe. Karel Vasak, p. 516

- Die Entwicklung des internationalen Menschenrechtsschutzes, p. 1757

36. The Council of Europe - K. Vasak, p. 463

37. Art. 45 ACHR and Art. 24 ECHR

38. Theory and Practice of the ECHR. Dijk and Hoof, p. 31.

39. Art. 44 ACHR and Art. 25 ECHR

40.Theory and Practice of the ECHR. Dijk and Hoof, p. 8

41. The Distinguishing Criteria of Institutions. K. Vasak, p. 218.

42. - Art. 27 of the Regulations of the Inter-American Commission

- Art. 24 and 25 ECHR

43. Art. 28 ECHR and Art. 48 (f) ACHR

44.Art. 50 of the Rules of Procedure of the European Commission

45. Art. 49 ACHR 